\title{
A very rare postcholecystectomy complication
}

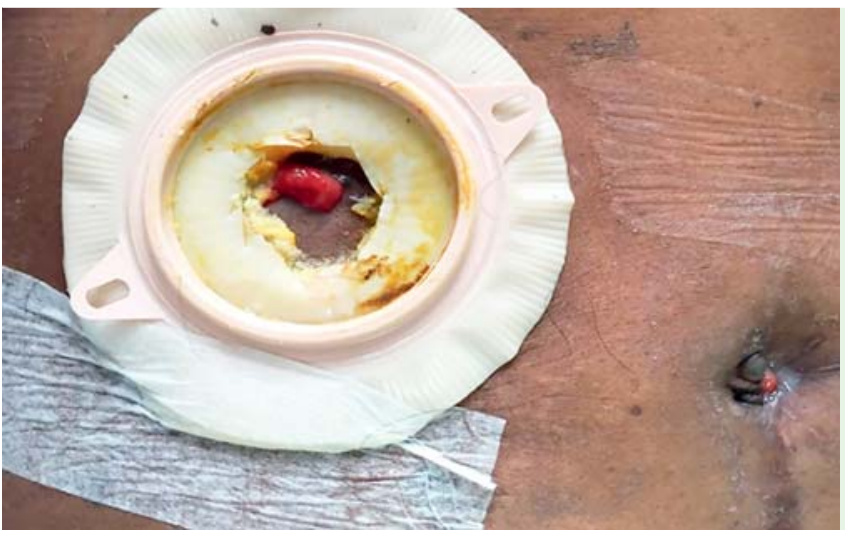

Fig. 1 Bilious enteric secretion through the drainage orifice.

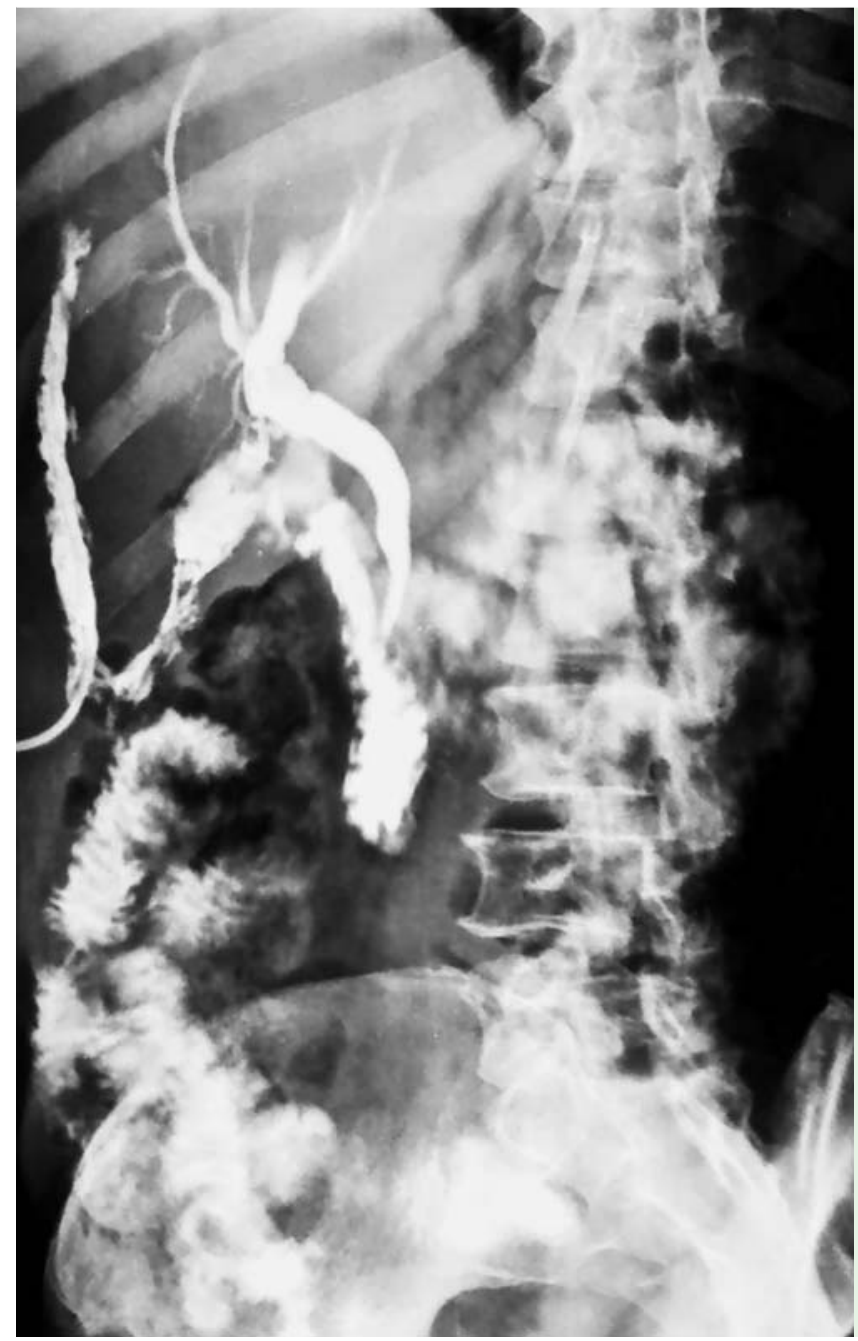

Fig. 2 Transcutaneous fistulography showing contrast in the colon and biliary tract.

A 53-year-old woman underwent elective laparoscopic cholecystectomy for choledocholithiasis. Two days later, she presented abdominal pain, leucocytosis, and subhepatic collection on ultrasonography. The patient was referred for emergency laparoscopy with drainage of the collection.

Around the 35th postoperative day, she developed a bilious enteric secretion through the drainage site ( $\bullet$ Fig. 1 ). Transcutaneous fistulography showed a

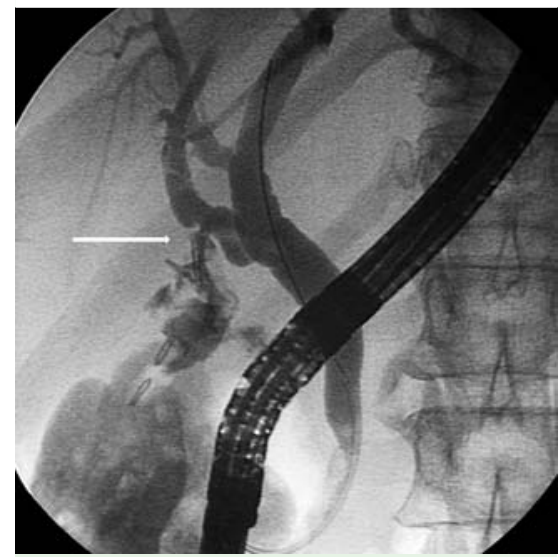

Fig.3 Endoscopic retrograde cholangiopancreatography confirmed a right hepatic duct fistula (arrow) to the colon.

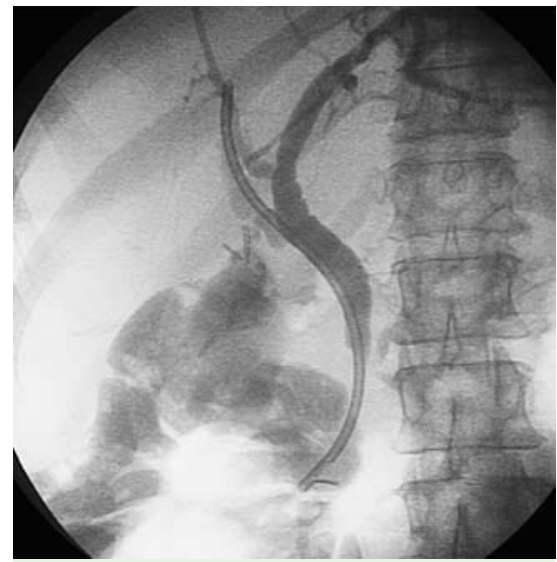

Fig.4 A $10 \mathrm{Fr} / 12 \mathrm{~cm}$ plastic stent was inserted into the right hepatic biliary duct.

biliary-colonic fistula, with contrast in the colon and biliary tract ( $\bullet$ Fig. 2 ). Endoscopic retrograde cholangiopancreatography (ERCP) was performed and confirmed the fistulography results $(\triangle$ Fig.3): a right hepatic duct fistula to the colon. A papillotomy was performed, and a $10 \mathrm{Fr} / 12 \mathrm{~cm}$ plastic stent was inserted ( $\bullet$ Fig. 4).

At colonoscopy 35 days later, there was no sign of the fistula. Around the 40th day, a second ERCP was performed to remove the plastic stent. During this procedure, no evidence of the fistula was seen; the cutaneous fistula had also closed ( $\bullet$ Fig.5). The patient had an uneventful recovery.

Biliary-colonic fistula is a very rare disease, usually secondary to a local infectious process or iatrogenic causes [1]. The 


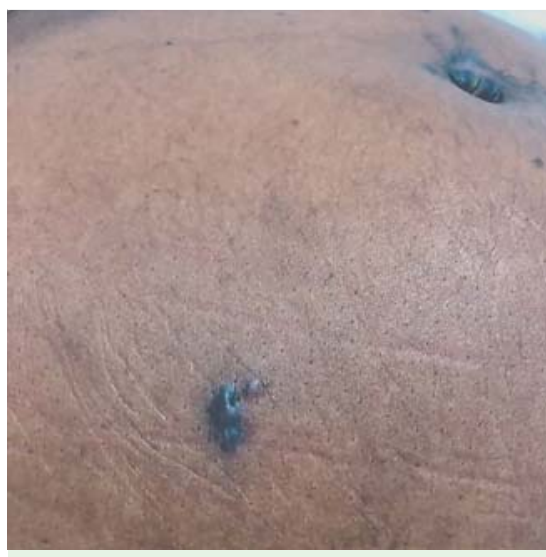

Fig. 5 Closure of the cutaneous fistula.

most common types are the choledochoduodenal (70\%) and the choledochocolonic (26\%) fistulae [2]. Clinical signs of biliary-colonic fistula include right upper quadrant pain, vomiting and nausea, associated with or without peritoneal signs, and even sepsis [3]. Diagnostic management includes ultrasound, computed tomography, percutaneous transhepatic cholangiography, magnetic reso- nance cholangiopancreatography, and ERCP. The gold standard treatment is surgical (open cholecystectomy and segmental colonic resection) [2]. However, ERCP and sphincterotomy may reduce the intrabiliary pressure and help the fistula to close itself. Such an approach can be the treatment of choice in some cases [4].

Very few cases of biliary-colonic fistula have been reported in the literature, and most of them were treated with surgery. The case described here, however, was treated successfully by using the ERCP approach.

\section{Endoscopy_UCTN_Code_CPL_1AM_2AZ}

\section{Competing interests: None}

\section{Hugo Gonçalo Guedes ${ }^{1}$,} Everson L. A. Artifon 1,2

${ }^{1}$ Department of Surgery, University of São Paulo Medical School, São Paulo, Brazil

2 Endoscopy Division, Ana Costa Hospital, Santos, Brazil

\section{References}

1 Rice JP, Spier BJ, Soni A. Preoperative diagnosis of cholecystocolonic fistula on ERCP. N Z Med J 2010; 123: 69-72

2 Smyth J, Dasari BV, Hannon R. Biliary-colonic fistula. Clin Gastroenterol Hepatol 2011; 9: A26

3 Macedo FI, Casillas VJ, Davis JS et al. Biliarycolonic fistula caused by cholecystectomy bile duct injury. Hepatobiliary Pancreat Dis Int 2013; 12: $443-445$

4 Toll EC, Kelly MD. Successful management of cholecystocolic fistula by endoscopic retrograde cholangiopancreatography: a report of two cases. Hong Kong Med J 2010; 16 : $406-408$

Bibliography

DOI http://dx.doi.org/

10.1055/s-0042-105645

Endoscopy 2016; 48: E156-E157

(c) Georg Thieme Verlag KG

Stuttgart · New York

ISSN 0013-726X

\section{Corresponding author}

Hugo Gonçalo Guedes, MD

Department of Surgery

University of São Paulo Medical School

Carvalho Aguiar, 255

7 andar

São Paulo - SP 05422-090

Brazil

Fax: +55-11-26616221

hugogguedes@yahoo.com.br 